\title{
Seizure and Hepatosplenomegaly- Rare Manifestation of Parvovirus B-19: A Case Report and Review of the Literature
}

\author{
Yadav Kamlesh, ${ }^{1}$ Gupta Pallav, ${ }^{1}$ Murari Manjula, ${ }^{1}$ and Malik Rohan ${ }^{2}$ \\ ${ }^{1}$ Department of Pathology, Sanjay Gandhi Postgraduate Institute of Medical Sciences, Lucknow 226014, India \\ ${ }^{2}$ Department of Pediatric Gastroentology, Sanjay Gandhi Postgraduate Institute of Medical Sciences, Lucknow 226014, India
}

Correspondence should be addressed to Yadav Kamlesh, kamleshyadava81@gmail.com

Received 27 November 2010; Accepted 7 April 2011

Academic Editor: Jean-Paul Gonzalez

Copyright (c) 2011 Yadav Kamlesh et al. This is an open access article distributed under the Creative Commons Attribution License, which permits unrestricted use, distribution, and reproduction in any medium, provided the original work is properly cited.

\begin{abstract}
Parvovirus B19 is the etiologic agent of erythema infectiosum (fifth disease), a fever-rash illness occurring in childhood. We present a 10 month old child with high grade fever for 10 days, generalized tonic-clonic seizure, bilateral cervical lymphadenopathy, generalized maculopapular rash, hematemesis and malena. Bone marrow aspiration and liver biopsy were done. EBV serology and parvovirus PCR were also performed. Bone marrow aspiration and biopsy showed giant pro-erythroblast consistent with parvovirus infection. PCR showed amplification of parvovirus genomic sequences. Present case highlights an atypical presentation of Parvovirus B19 infection as fever, rash and hepatosplenomegaly.
\end{abstract}

\section{Introduction}

Parvovirus B19 is the etiologic agent of erythema infectiosum (fifth disease), a fever/rash illness occurring in childhood. In adults it causes varying degree of aplastic anemia usually in immunocompromised hosts due to organ transplant or immunodeficiency syndromes. Systemic manifestation of infection includes multisystem involvement and viral hemophagocytic syndrome.

Hepatitis and encephalitis resulting in hepatosplenemegaly and seizure may also be caused by parvovirus, however incidence is very rare [1]. Very few case reports exist in the literature with a clinical manifestation of fever, rash, hepatosplenomegaly, and seizure as a result of parvovirus infection.

Herein we describe a case presenting with fever, rash, hepatosplenomegaly, and seizure due to parvovirus infection.

\section{Case Report}

A 10-month-old child presented with high-grade fever for 10 days followed by three episodes of generalized tonicclonic seizure. Subsequently patient developed bilateral cervical lymphadenopathy, generalized maculopapular rash, hematemesis, and melena. On examination child was irritable with weight $7.5 \mathrm{~kg}$, height $71 \mathrm{~cm}$, head circumference $41 \mathrm{~cm}$, mild pallor, and healed ulcers in oral cavity. Liver span was $4.5 \mathrm{~cm}$ firm with rounded margin, coarse ecotecture on USG, and spleen was palpable $4.0 \mathrm{~cm}$ below left costal margin.

With the previous presentation, differential diagnosis of postviral hemophagocytosis/infiltrative disorders was kept. On investigation total leukocyte count was high with lymphocytosis, and peripheral smear showed activated lymphocytes. Fibrinogen was low, ferritin was high, and triglyceride was raised (Table 1). Bone marrow aspiration and liver biopsy were done. EBV serology and parvovirus PCR were also performed. Bone marrow aspiration and biopsy showed giant proerythroblast consistent with parvovirus infection (Figures 1 and 2). CSF culture was sterile. PCR showed amplification of parvovirus genome. Upper gastrointestinal endoscopy was done and was normal. No abnormality was detected to explain hematemesis. Liver biopsy showed mild nonspecific steatohepatitis. Serology for human immunodeficiency virus was negative.

Patient was managed conservatively with oral antibiotic, vitamins, and hematinics. Child was afebrile at discharge with persistent hepatosplenomegaly. 
TABLE 1: Laboratory profile.

\begin{tabular}{|c|c|c|}
\hline Hemogram & Urine & Blood chemistry \\
\hline $\mathrm{Hb}=9.7 \mathrm{gm} / \mathrm{dl}, \mathrm{TLC}=$ & Culture: positive for & Total protein $=6.4 \mathrm{~g} / \mathrm{dL}$ \\
\hline $37000 /$ cumm & Klebsiella pneumonae. & Albumin $=2.6 \mathrm{~g} / \mathrm{dL}$ \\
\hline PLT : $2,44,000 /$ cumm & BACTEC (aerobic) & Amylase $=44 \mathrm{U} / \mathrm{L}$ \\
\hline DLC:P24, L71, E01, & bacterial culture & $\mathrm{SGOT}=131 \mathrm{U} / \mathrm{L}$ \\
\hline M02, & sensitivity: & $\mathrm{SGPT}=105 \mathrm{U} / \mathrm{L}$ \\
\hline Red cell indices & Coagulase negative & $\mathrm{GGT}=802 \mathrm{U} / \mathrm{L}$ \\
\hline (1) $\mathrm{MCV}=79 \mathrm{fl}$, & Staphylococcus, sensitive & $\mathrm{LDH}=695 \mathrm{U} / \mathrm{L}$ \\
\hline (2) $\mathrm{MCH}=25.6 \mathrm{pg}$, & to Vancomycin. & Alkaline phosphatase: 469 \\
\hline (3) $\mathrm{MCHC}=32.4 \%$, & & Total bilirubin: $1.2 \mathrm{mg} / \mathrm{dL}$ \\
\hline Reti $=0.5$ & & Conjugated bilirubin $=$ \\
\hline PS: normocytic & & $0.7 \mathrm{mg} / \mathrm{dL}$ \\
\hline \multirow[t]{2}{*}{ hypochromic } & & Fibrinogen: $122 \mathrm{mg} / \mathrm{dL}$ \\
\hline & & Ferritin: $822 \mu \mathrm{g} / \mathrm{L}$ \\
\hline
\end{tabular}

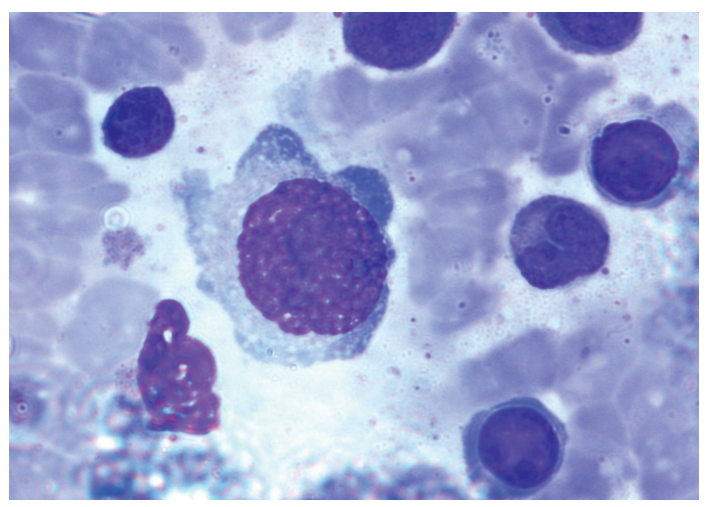

FIGURE 1: Bone marrow aspiration showing giant proerythroblast with prominent nucleoli and cytoplasmic blebs. Myeloid cells were relatively increased.

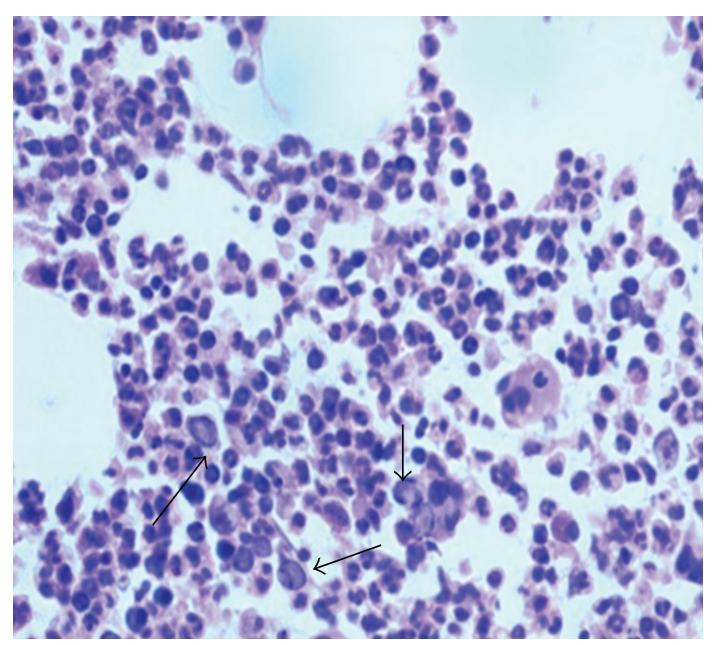

FIGURE 2: Bone marrow biopsy showing giant proerythroblast, nuclear clearing with eosinophilic intranuclear inclusion and peripheral condensation of chromatin. Late erythroid precursors are reduced, and myeloid cells are increased.
TABLE 2: Laboratory profile.

\begin{tabular}{lll}
\hline Serology & $\begin{array}{l}\text { Bone marrow } \\
(\mathrm{BM})\end{array}$ & Liver biopsy \\
\hline EBV ELISA: negative & $\begin{array}{l}\text { BM aspiration and } \\
\text { biopsy: giant } \\
\text { proerythroblasts, } \\
\text { s/o parvovirus } \\
\text { HAV, HBV, HCV: }\end{array}$ & $\begin{array}{l}\text { Nonspecific } \\
\text { steatohepatitis }\end{array}$ \\
negative & infection & \\
Parvovirus PCR: positive & & \\
\hline
\end{tabular}

At follow up patient was afebrile. On ultrasonography liver span and spleen were normal. The hematological and biochemical parameters were within normal limit.

\section{Discussion}

Acute infection of parvovirus in childhood causes fever rash illness known as "erythema infectiusum" or "fifth disease". Disease is characterized by fever, rash, constitutional symptoms and is self-limiting. In immunocompetent adult hosts virus causes acute symmetric polyarthropathy. In immunocompromised adult host chronic infection of parvovirus B19 causes variable degree of erythroid hypoplasia and in severe form leads to pure red cell aplasia. The pathogenesis may be due to its tropism and direct cytotoxicity to erythroid progenitor cells [2].

Nervous system involvement of parvovirus infection is rare and usually manifest as meningitis, encephalitis, and very rarely seizure episode $[3,4]$. Hepatic involvement is also very rare and usually seen in cases of coinfection with other hepatotropic viruses [1]. Simultaneous involvement of CNS and liver resulting in encephalitis, hepatitis, and hepatosplenomegaly is exceptionally rare, and very few case reports are available in the literature [1]. Parvovirus causes anemia due to selective erythroid tropism resulting in hypoplasia. Exact pathologic mechanism of erythroid hypoplasia is not clear; however receptor for virus on 
erythroid precursor cells is a likely mechanism. Pathologic mechanism of meningitis, encephalitis, and hepatitis is also unclear. This immunocompetent child presented with self limiting fever, hepatitis, hepatosplenomegaly, and seizure. $\mathrm{He}$ was managed conservatively and was stable at discharge.

\section{Conclusion}

We present this case of 10-month-old immunocompetent male child presenting with seizure, fever, rash with a bone marrow and PCR diagnosis of parvovirus infection for its extremely rare presentation with encephalitis and hepatosplenomegaly.

In the light of the present experience, the diagnosis of parvovirus B19 acute infection should be considered in any case of acute febrile illness with seizure, rash, and hepatosplenomegaly.

\section{Conflict of Interests}

The authors declare no conflict of interests.

\section{References}

[1] J. Kishore and M. Sen, "Parvovirus B19-induced thrombocytopenia and anemia in a child with fatal fulminant hepatic failure coinfected with hepatitis A and E viruses," Journal of Tropical Pediatrics, vol. 55, no. 5, pp. 335-337, 2009.

[2] E. D. Heegaard and K. E. Brown, "Human parvovirus B19," Clinical Microbiology Reviews, vol. 15, no. 3, pp. 485-505, 2002.

[3] A. Okumura and T. Ichikawa, "Aseptic meningitis caused by human parvovirus B19," Archives of Disease in Childhood, vol. 68, no. 6, pp. 784-785, 1993.

[4] H. H. Balfour, G. M. Schiff, and J. E. Bloom, "Encephalitis associated with erythema infectiosum," The Journal of Pediatrics, vol. 77, no. 1, pp. 133-136, 1970. 


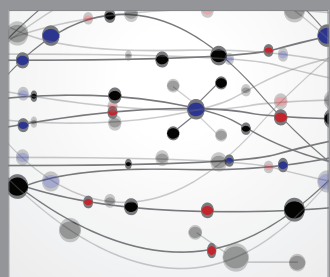

The Scientific World Journal
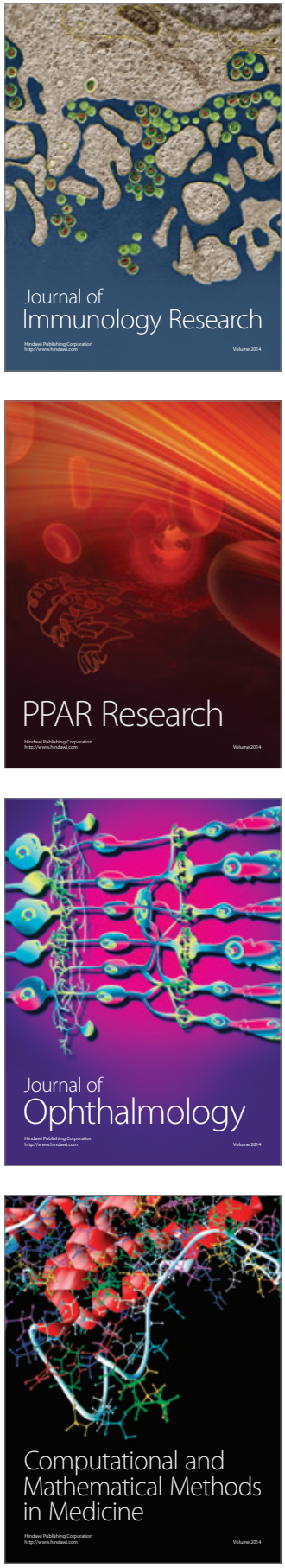

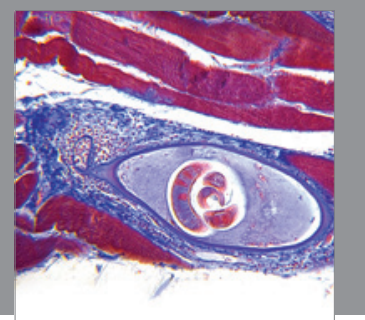

Gastroenterology

Research and Practice


\section{Hindawi}

Submit your manuscripts at

http://www.hindawi.com
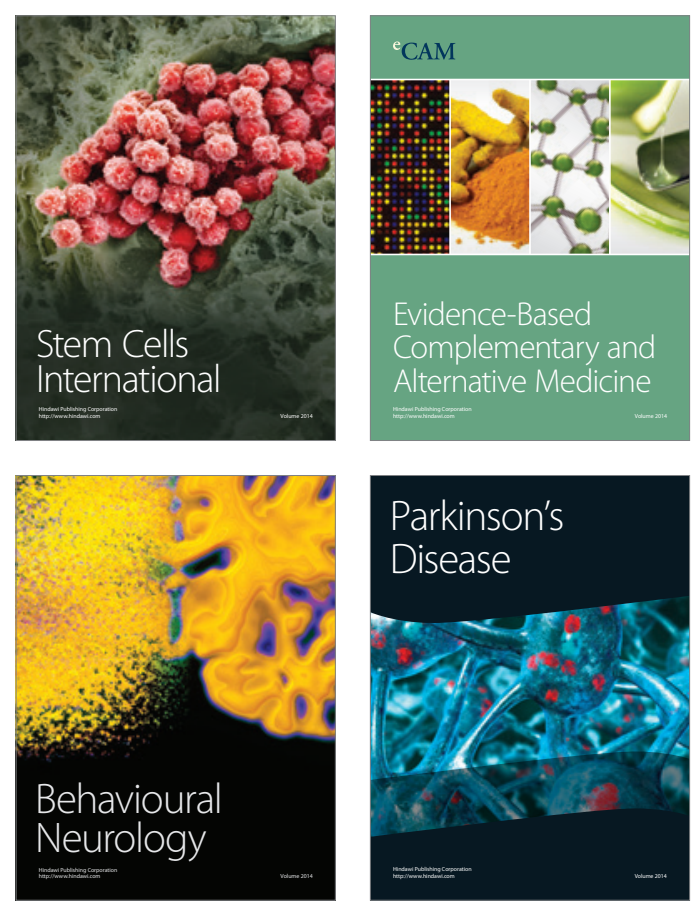

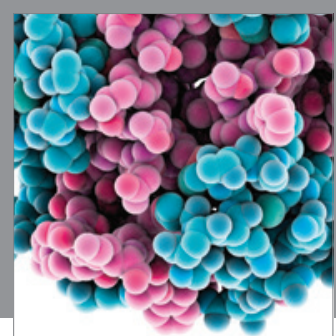

Journal of
Diabetes Research

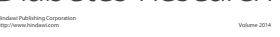

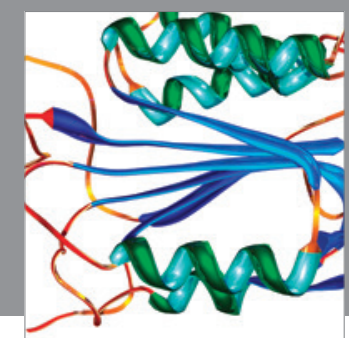

Disease Markers
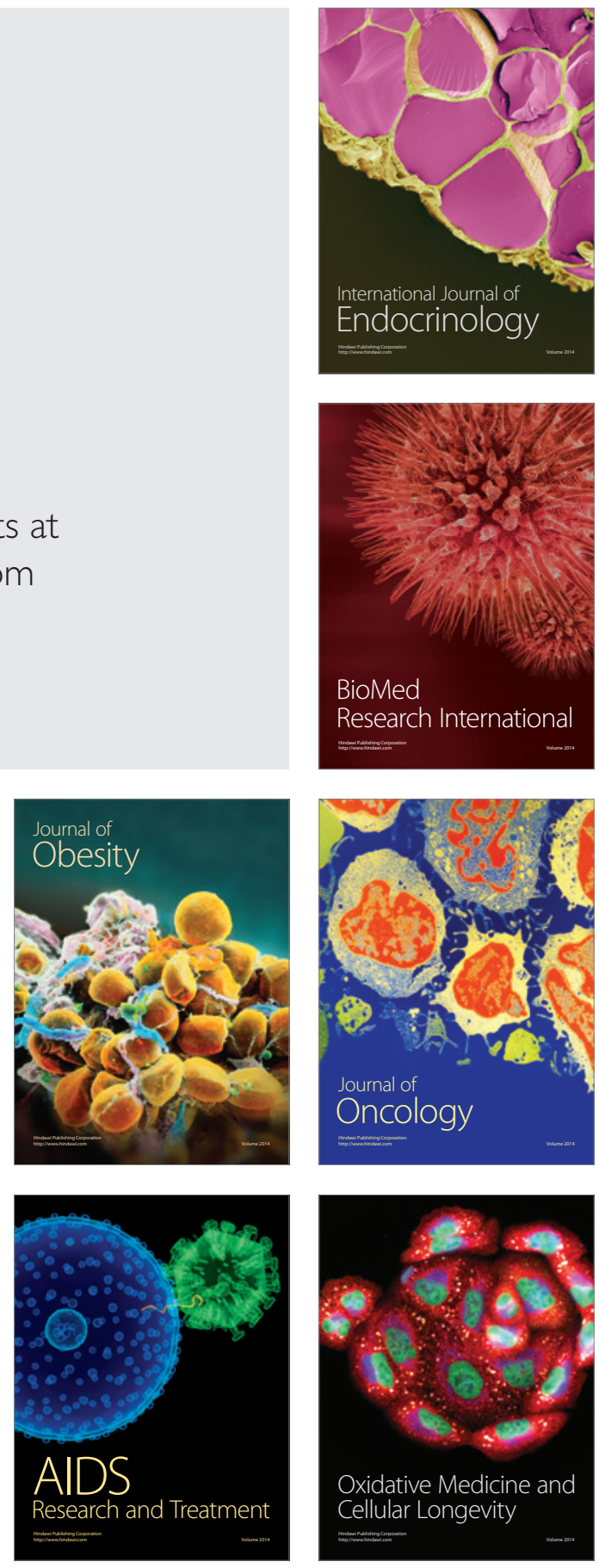